\title{
An Improved Supplier Driven Packaging Design and Development Method for Supply Chain Efficiency
}

Sohrabpour, Vahid; Oghazi, Pejvak; Olsson, Annika

\author{
Document Version \\ Accepted author manuscript \\ Published in: \\ Packaging Technology and Science
}

DOI:

10.1002/pts.2194

Publication date:

2016

License

Unspecified

Citation for published version (APA):

Sohrabpour, V., Oghazi, P., \& Olsson, A. (2016). An Improved Supplier Driven Packaging Design and Development Method for Supply Chain Efficiency. Packaging Technology and Science, 29(3), $161-173$. https://doi.org/10.1002/pts.2194

Link to publication in CBS Research Portal

\section{General rights}

Copyright and moral rights for the publications made accessible in the public portal are retained by the authors and/or other copyright owners and it is a condition of accessing publications that users recognise and abide by the legal requirements associated with these rights.

\section{Take down policy}

If you believe that this document breaches copyright please contact us (research.lib@cbs.dk) providing details, and we will remove access to the work immediately and investigate your claim.

Download date: 26. Apr. 2023
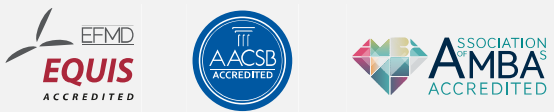


\section{An Improved Supplier Driven Packaging Design and Development Method for Supply Chain Efficiency}

\section{Vahid Sohrabpour, Pejvak Oghazi, and Annika Olsson}

Journal article (Post print version)

This is the peer reviewed version of the following article: An Improved Supplier Driven Packaging Design and Development Method for Supply Chain Efficiency. / Sohrabpour, Vahid; Oghazi, Pejvak; Olsson, Annika. In: Packaging Technology and Science, Vol. 29, No. 3, 2016, p. 161-173, which has been published in final form at http://dx.doi.org/10.1002/pts.2194. This article may be used for noncommercial purposes in accordance with Wiley Terms and Conditions for Self-Archiving."

Uploaded to Research@CBS: September 2016 
The research in this article put forward a supply chain focused packaging design and development method. The method better captures and satisfies the needs placed on packaging throughout the supply chain. The steps in the figure were developed by using: the four domains of design, design for packaging logistics (DFPL), three-dimensional concurrent engineering (3DCE), an expanded operational life cycle, and Packaging Requirement Cascading (PRC) from an industrial case study. The needs are found and categorized from the supply chain on the left side and go through the development steps on the right. The final packaging solution has to reduce the gap between supply chain needs and satisfaction and increase efficiency.

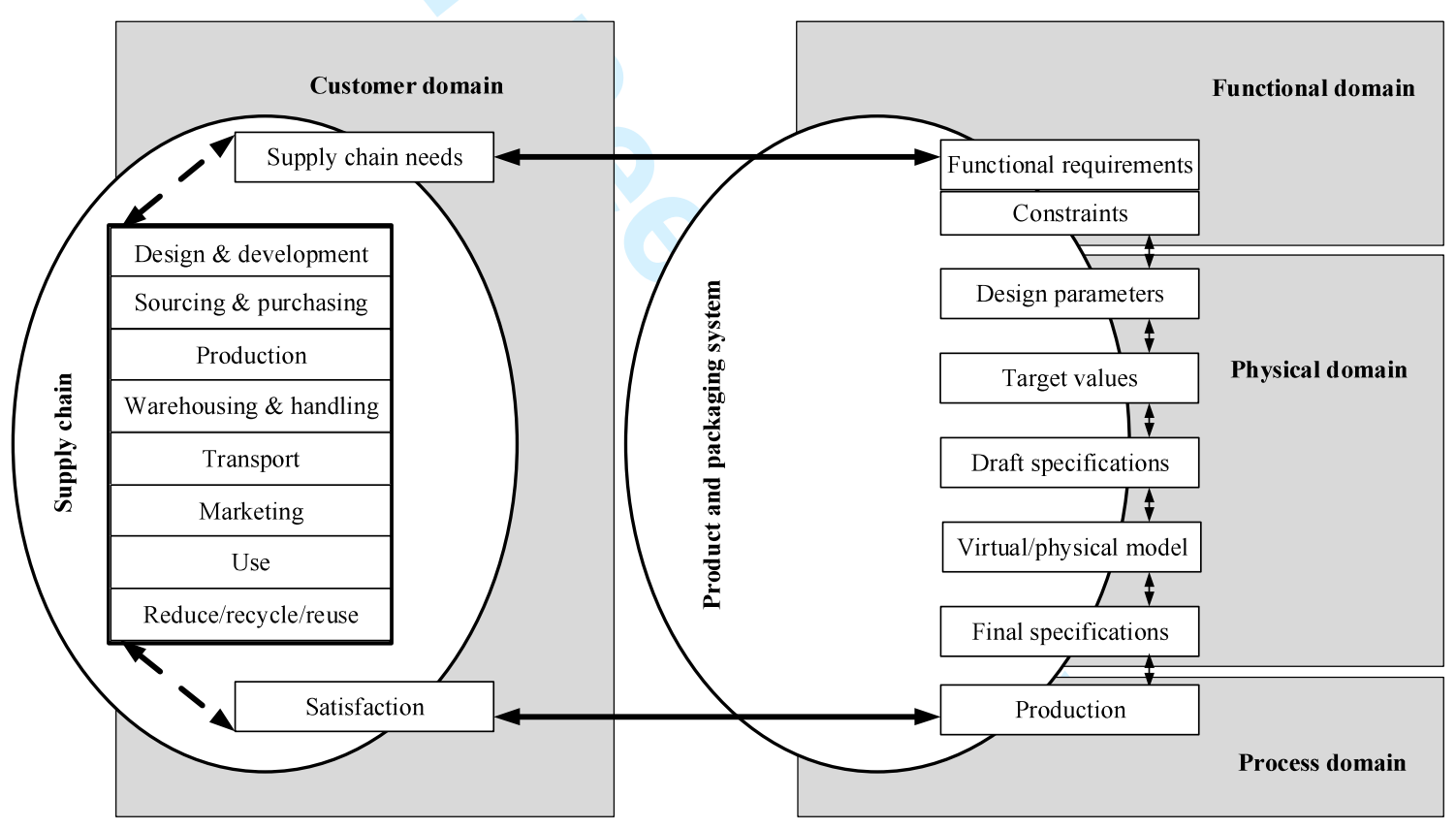




\title{
An Improved Supplier Driven Packaging Design and Development Method for Supply Chain Efficiency
}

\begin{abstract}
Packaging and the role it plays in supply chain efficiency is overlooked in most design and development research. An opportunity exists to meet the needs of supply chains to increase efficiency. This research presents three propositions on how to reduce the gap between supply chain needs and satisfaction in interaction with the product and packaging system. It also proposes a supply chain focused packaging design and development method to better satisfy supply chain needs placed on packaging. An extensive literature review was conducted and a Tetra Pak derived case study developed. The propositions were formulated and became the basis for improving Tetra Pak's existing packaging design and development method by better integrating supply chain needs. This was accomplished by using an expanded operational life cycle perspective that includes the entire supply chain. The resulting supply chain focused packaging design and development method enables improved supply chain efficiency while considering the product, the processes and cost.
\end{abstract}

Key words: supply chain; packaging design and development; operational life cycle; development method

\section{INTRODUCTION}

Attaining and maintaining supply chain efficiency is a key focus area for industry and academic research. Based on an efficiency perspective (e.g. $[1,2,3,4])$, packaging is regarded as a means to minimise the costs of delivery while maximising sales [5]. Packaging is thus a fundamental component in the supply chain with a significant impact on logistics costs and performance [6,7], while fulfilling needs in the interface between the supply chain and its main customers for supply chain effectiveness [1,2].

Packaging in many industries is conventionally regarded as having a subordinate role in product design [8]. Because of this, it is often delayed or even omitted in the development process. Design for supply chain management $[9,10]$ focuses solely on the product and does not address packaging in the supply chain. Yet a common reason for package redesign is that the package does not meet the supply chain needs [11]. Figure 1 shows this potential gap between supply chain needs and satisfaction, and what commonly happens when packaging design is not carried out in tandem with product development or when packaging does not account for supply chain needs. The supply chain system thus has to interact with the product and packaging system in order to satisfy one another's needs for attaining and maintaining effectiveness and efficiency. In this way, packaging can meet supply chain needs (e.g. production and transport) and perform its functions in relation to the product (e.g. containment, preservation and protection). 
$<$ Place Figure 1 about here $>$

A problem in practice is the scarcity of packaging design and development practices that address supply chain needs. What product developers perceive as well-designed and suitable packaging is not necessarily the best for an efficient supply chain [1].

Consequently, methods that can reduce the gap illustrated in Figure 1 are required. This research presents three propositions on how to reduce the gap and proposes a supply chain focused packaging design and development method to better capture and satisfy the needs placed on packaging by food supply chain actors. The proposed method is based on exploring, analysing and improving an existing design and development method used by Tetra Pak, a global food packaging supplier. The three propositions are based on a combination of a review of the literature in the field and the empirical input from the TetraPak case.

The paper is organised as follows: The next section presents the theoretical background on product and packaging in the supply chain and on the related design and development methods. The three propositions are also presented. The research method and the case study are then described followed by the results, analysis and discussion section. The paper concludes with implications, conclusions and suggestions for further research. The appendix provides an example of the application of the packaging design and development method used by the case company.

\section{PRODUCT AND PACKAGING IN THE SUPPLY CHAIN}

The product and packaging make up a system that is a part of the physical flow of supply chains. Figure 2 illustrates a model based on a systems perspective that emphasises the interrelations and interdependence between the product and the three levels of packaging: primary, secondary, and tertiary $[11,12]$.

$<$ Place Figure 2 about here $>$

There are many perspectives to consider in supply chain management. This is because of the different operations and production processes required in the flow of goods within the supply chain. These include sourcing, purchasing, warehousing, logistics, marketing, production, product development, and the environment [13]. Saghir [14] defines packaging as "a coordinated system of preparing goods for safe, secure, efficient and effective handling, transport, distribution, storage, retailing, consumption and recovery, reuse or disposal combined with maximising consumer value, sales and hence profit." Packaging in supply chains, has multiple and diverse functions, such as apportionment, communication, containment, convenience, information, preservation, promotion, protection, unitisation, waste reduction and recycling $[15,16,17]$.

Several authors, based on their disciplinary perspectives, have highlighted operations that need to be considered when developing packaging systems (e.g. [2,11,18,12,19]). Rundh [20] focuses on the challenges that packaging design and development face in relation to supply 
chain operations considering distribution and retail marketing. The supply chain perspective is acknowledged, but the focus is on the needs of the end user. Azzi et al. [8] take an interdisciplinary perspective and suggest five main drivers to consider in packaging design and development: safety, ergonomics, sustainability, logistics, marketing and communication. They consider logistics in relation to packaging (i.e. packaging logistics), which focuses on the synergies of integrating packaging and logistics to increase supply chain efficiency and effectiveness [8,21,13]. In product design and development, Olsson [22] considers development, production, distribution, use and reduce/recycle/reuse.

Garcia and Prado [23] provide an integrated management model for packaging design and development from a supply chain perspective. They define a few requirements and address three main needs: logistics, marketing, and environmental. Their framework addresses how existing packaging systems affect supply chains from different organisational functions and processes. However, the focus is not on how to handle and prioritise technical requirements for new packaging design and development.

From a managerial and practical standpoint, Van Hoek and Chapman [24] claim that supply chain managers are often the last to find out about new product development. Thus, they propose a framework for improving product design and supply chain alignment by involving the customer's warehouse and store staff at an early point in product design and development. The framework includes supply chain needs but overlooks the role of packaging.

\section{Operational life cycle}

Focusing on supply chain operations rather than the product, Sarkis [25] suggests using the term "operational life cycle" in the interface between product development and supply chain operations. It typically includes procurement, production, distribution and reversed logistics. Packaging has a strong relationship with these components of the operational life cycle [25].

The operational life cycle by Sarkis [25], however, does not include many of the operations in the supply chain that product and packaging goes through. An even more comprehensive approach to categorise supply chain needs - using Sarkis, Sohrabpour et al., Rundh and Olsson [11,20,25,22] - would include design and development, sourcing and purchasing, production, warehousing and handling, transport, marketing, use, and reduce/recycle/reuse. Using a supply chain focused perspective when developing packaging can ensure that the supply chain needs are met and satisfied (Figure 1). This would enhance the operational efficiency in the supply chain since packaging is regarded as the single most important interface between the product and the logistics system [2].

Based on the results of Sohrabpour et al., Rundh, Sarkis and Olsson [11,20,25,22], an expanded operational life cycle as illustrated in Figure 3 was developed. Compared to Sarkis' [25], it considers a collection of challenges and needs in the supply chain regarding the product and packaging system identified by Sohrabpour et al., Rundh, Sarkis and Olsson $[11,20,25,22]$. This resulted in the first of three propositions on which the proposed supply chain focused packaging design and development method is based.

$<$ Place Figure 3 about here $>$ 
Proposition 1: Improve the packaging design and development method by using an expanded operational life cycle.

The needs placed on the product and packaging systems along the supply chain are integrated by using an expanded operational life cycle perspective. There are four domains to consider in the design: customer, functional, physical and process. All designs involve continuous processing of information between and within these domains [26,27,28]. In the domains, customer attributes (or needs), functional requirements and constraints, design parameters and process variables are connected by means of mapping. This is illustrated in Figure 4, starting from the left by determining "What" to achieve and progressing to the right to "How", which embodies the design solution based on the needs identified [27].

$<$ Place Figure 4 about here $>$

The Package Requirement Cascading (PRC) method was developed and used by Tetra Pak based on Olsson's conceptual design [22], which is why PRC is central to the empirical study presented in this paper. Chen's [26] four domains of design were found suitable for analysing the PRC method. In the PRC process, needs are input to packaging design and development and mapped to requirements in the functional domain in parallel with the consideration of external constraints. The requirements and external constraints are then mapped to the design parameters (i.e. technical attributes, target values and specifications) in the physical domain.

To overcome the limitations of the PRC method in mapping the needs and translating them into packaging requirements for the supply chain, Proposition 2 is put forward to enhance the needs-finding phase.

Proposition 2: Use the four domains of design to improve packaging design and development methods in logistics.

The four domains of design were blended with design for packaging logistics (DFPL) and three-dimensional concurrent engineering (3DCE) for better integration of supply chain needs in design and development.

\section{DFPL}

For logistics to be included in package design, Klevås and Saghir [1] introduced design for packaging logistics (DFPL). DFPL shows how to improve packaging and logistics related activities and the interrelations between them to increase supply chain efficiency and effectiveness [14]. The logistical needs are transport, inventory, warehousing, and order processing. However, it only provides broad guidelines for considering the synergies between packaging systems and logistics. 
3DCE considers the product, process and supply chain from a design and development perspective [29,30,31,32]. One dimension, product design and development, focuses on product specifications; another dimension, process design, considers manufacturing methods, facilities, equipment and output; and a third dimension, supply chain design, deals with logistical channels, customers and suppliers, relationships among members of a supply chain, insourcing and outsourcing [31].

Ellram et al. [31] provide an example of a large consumer products firm. It improved performance and lowered costs by conducting an end-to-end supply chain analysis (e.g. auditing logistics and manufacturing), and by engaging all inside and outside functional areas of the firm that interacted with a given product. As a result, the firm improved its processes, its supply chain operations, and packaging. This interesting example views packaging design as a part of product design. Dominic [33] also puts forth a conceptual holistic packaging design and development method inspired by 3DCE.

3DCE can be used to overcome DFPL's limitation of not considering processes. By building on the first two propositions, another limitation of DFPL (that it only provides broad guidelines and not a specific method for packaging design and development) can also be addressed.

Proposition 3: Integrate the product and packaging system, supply chain and processes in design and development.

By considering the concurrent development of product and packaging [34,35] as a system in relation to logistics and supply chain design, the competitive advantage of the firm and the whole supply chain will be enhanced [34].

\section{METHOD AND CASE DESCRIPTION}

A case study at Tetra Pak, a global packaging supplier for liquid food supply chains, allowed the researcher to become deeply involved in the case organisation enabling observations, indepth access to experts and internal data for analyses of phenomena that would have otherwise been inaccessible for scientific investigation [36].

The case study investigated how the design and development method was used in the company. The study focused on ambient milk supply chains in developing countries (see Figure 5). The ambient milk was packed in Tetra Fino Aseptic, Tetra Wedge Aseptic or in Tetra Classic Aseptic as primary packages and then transported in corrugated board secondary packaging. However, ambient food and non-food supply chains tend to be set up in similar ways with the same operational steps, and with products that are produced at different locations still ending up in similar retail outlets. The proposed method can be used as a basis for food and non-food packaging applications. Nevertheless, the method would have to be adapted to the specific company context, processes, supply chains and products. 
To establish construct validity according to Yin [36], multiple sources of data were used:

- Internal documentation: design and development manuals and documents from previous packaging design and development projects.

- Observations: One of the authors was employed at the company for the 27-month duration of a collaborative research effort between academia and industry. This enabled input through direct participant observations in projects which provided unique insights into the activities studied by the observer [37].

- Interviews: Semi-structured interviews were conducted with seven internal company experts: two project managers, three packaging development engineers, one system engineer, and one packaging design manager. Interviewing experts is regarded as an efficient and concentrated data collection method [38]. The interviews were conducted based on snowballing in data collection to reach theoretical saturation according to Corbin and Strauss [39]. The data were collected by writing field notes, and followups were conducted to clarify the data [40]. The data were stored in a database for establishing reliability based on Yin [36].

Themes from the literature review, which was conducted iteratively during the case study, were used to analyse the data. Thus, the four domains of design were used in combination with the PRC, and adjusted with DFPL and 3DCE to analyse the data. The final results were reviewed by an expert who served as a key informant reviewer at the case company.

\section{PRC method description}

The PRC takes place in five steps: 1) collection and structuring the needs, 2) weighting the needs, 3) breaking them down into requirements, 4) adding technical attributes, 5) correlating requirements with technical attributes. The PRC also includes two main matrices: the Criteria Search Matrix (CSM) and the Breakdown and Correlation Matrix. An example of using the PRC for the development of corrugated board secondary packaging is provided in the Appendix.

In order to collect, structure and translate the needs to tangible requirements, the company developed the CSM, also based on Olsson's theory [22]. The initial needs identified are generally described on a high level (e.g. low cost of secondary packaging). To deeply understand the effects on a packaging solution, the needs are broken down into more tangible requirements. For example, the low cost of secondary packaging is broken down into material usage and production related costs, all of which affect the final cost. These requirements are weighted in relation to how important each one is to the given need. The requirements are then used to design and evaluate packaging proposals.

Then the Breakdown and Correlation Matrix is used. The weighted needs are broken down and correlated to requirements and technical attributes in order to prioritise the latter. For example, the need to withstand palletising can come under the distribution category, and be correlated to requirements regarding pallet pattern and stacking stability.

The technical attributes of the packaging are added to find the solution that fulfils relevant needs and requirements, such as pallet size and box counts (number of units per container), as well as the technical characteristics of the packaging material. The technical attributes are calculated after finishing the correlation, the weighting of needs, requirements and evaluation criteria. Each attribute that is correlated to any criteria will then be prioritised in a table in order of importance resulting in the draft specifications. 
The PRC outputs constitute the most important part of the method and are included in draft specifications of the packaging that embrace three major values: a prioritised list of the design parameters; organisational responsibility; and correlation between the needs, requirements and design parameters (technical attributes). The advantage of such documentation is that it enables one to follow the primary needs to the draft specifications of possible solutions. At TetraPak, the list has served as valuable input to packaging design. An example of this is that the box type is sometimes more important than working with pallet efficiency or adaption of the primary packaging and automated packers.

The prioritised list of the design parameters is necessary to create the most viable solution. Without such prioritisation the solution has to satisfy all the needs identified, which most likely is impossible. These design parameters constitute the specifications of the solution and since they are based on prioritisation, sub-optimisation can be avoided. Moreover, assigning organisational responsibility and determining the competences required are also important outputs as well as test methods and target values. It is often necessary to test the solution by using virtual and/or physical models before the production stage.

The results of the empirical portion of the research were analysed based on the three propositions.

\section{RESULTS, ANALYSIS AND DISCUSSION}

In the PRC method, much effort was put into breaking down needs and weighting them and less effort into considering and collecting needs from the supply chain. This original method was modified in this research using the three propositions.

Proposition 1: Improve the packaging design and development method by using an expanded operational life cycle.

The PRC method was adapted and improved by the authors to include details in order to design and develop packaging based on an expanded operational life cycle. This took into consideration the specific supply chain challenges and needs (e.g. $[11,20]$ ) (Figure 3 ) that were missing in the original method so that efficient packaging solutions for the supply chain could be developed in practice. Economic, legal, environmental (e.g. [41]) and other factors can be added to consider the consequences of external constraints on packaging design and development (Table 1).

$<$ Place Table 1 about here $>$

In the analysis of the PRC method, only three of the four domains of design [26,28] were covered: the customer, functional, and physical domains. Input from processes was only considered implicitly in primary packaging design and development as a part of the company's internal competences. In secondary packaging design and development, however, process domain was not addressed because of the lack of internal company knowledge on related production processes. Investigating the needs of production processes, such as the 
machinability, in the early needs-finding phase would most likely enhance the final solution, and be used as input in the customer domain.

Proposition 2: Use the four domains of design to improve packaging design and development methods in logistics.

The needs identified are mapped to requirements in the functional domain in parallel with the consideration of external constraints. Requirements and external constraints are then mapped to design parameters (i.e. technical attributes, target values and specifications) in the physical domain (Figure 6).

\author{
$<$ Place Figure 6 about here $>$
}

In order to categorise needs under the first domain of design, four evaluation criteria are employed in the CSM: process, environs, humans and economy. The process criterion is related to procedures (e.g. the packing machine procedure) and corresponds to process design in 3DCE. The environs criterion deals with the product's relation to its surroundings (e.g. space utilisation, durability in harsh environments). This corresponds to supply chain design in 3DCE. The human criterion embraces such aspects as ergonomic and aesthetical considerations to meet the purpose of the packaging (e.g. ergonomic handling). This corresponds to product design in 3DCE. Lastly, the economy criterion considers costs and the economic aspects of the product and is considered a constraint for the solution (e.g. material cost). This is not mentioned in the 3DCE concept, yet it is important for supply chain performance.

Use of the 3DCE concept and the supply chain focused CSM (Table 1) contributes to product and packaging system design and development because it considers production processes (production and reduce/recycle/reuse), supply chain design decisions (sourcing and purchasing) and product and packaging design and development. Sub-optimisation is taken into account in the three evaluation criteria - process, supply chain, product and packaging system - all covered by 3DCE. There is much conceptual research on 3DCE and examples thereof, but to the authors' knowledge, there is no previous design and development method that considers its three aspects in one method. By doing so, the proposed method offers opportunities to develop effective and efficient packaging. This is beneficial for industrial supply chain applications. The proposed method adds economic constraints as a fourth dimension beyond 3DCE.

Proposition 3: Integrate the product and packaging system, supply chain and processes in design and development.

The proposed packaging design and development method integrates supply chain needs and processes based on the expanded operational life cycle presented in Table 1. It is further integrated into the steps required in the four domains of design presented in Figure 7. 


\section{IMPLICATIONS AND CONCLUSIONS}

The research findings presented contribute to the body of knowledge in a number of areas. First, the results complement previous operational life-cycle based research by proposing that product and packaging system be considered from a supply chain perspective. What had originally been a product design and development method was adapted for packaging with a new supply chain focused perspective. The proposed method has the level of detail required to quantify and prioritise supply chain needs in contrast to the broad guidelines of DFPL.

Second, the results provide greater validity for the previous limited findings on the importance of the supply chain topic in product and packaging design and development. The results also highlight the role packaging plays in contributing to efficient supply chains.

A third contribution is the proposed method's extension of the limited operational life cycle (and its counterpart used by Tetra Pak, the packaging life cycle) into an expanded operational life cycle. This enables design and development methods to better map the needs of the entire supply chain. Thus, the research on the whole contributes to theory by improving the operational life cycle concept.

This study complements previous operational life-cycle based research and practice by including production processes. This enables early inclusion of the supply chain needs and production requirements in design and development. The proposed method provides a basis for developing more effective and efficient packaging solutions to increase supply chain efficiency. It contributes to collecting supply chain needs based on the expanded operational life cycle.

This research also contributes to product and packaging system design and development methods by matching the product and packaging system, process and supply chain in relation to 3DCE.

The proposed method can be used in a variety of industrial practices. Food and non-food packaging companies can consider the propositions in revising their packaging design and development.

Further research is suggested to validate and adapt the proposed method to the existing processes for implementation in organisations. Theoretical improvements of product and packaging design and development methods using 3DCE are suggested since its integration is limited. This is vital to establish a strong basis that enables simultaneous rather than separate considerations of the supply chain, processes, and product and packaging system.

\section{REFERENCES}

1. Klevås J, Saghir M. Introducing the concept of design for packaging logistics. ICPQR, Miami (FL), USA, 2004. 
2. Saghir M. Platform for Packaging Logistics Development - A Systems Approach, Doctoral thesis, Lund University: Lund, Sweden, 2004.

3. Olsmats C, Dominic C. Packaging scorecard - a packaging performance evaluation method. Packaging Technology and Science 2003; 16: 9-14. DOI:10.1002/pts.604

4. García-Arca J, Prado-Prado JC, Antonio-García-Lorenzo. Logistics improvement through packaging rationalization: a practical experience. Packaging Technology and Science 2006; 19: 303-308. DOI: 10.1002/pts.723

5. Paine FA. Fundamentals of Packaging, Brookside Press: Leicester, UK, 1981.

6. Ebeling CW. Integrated Packaging Systems for Transportation and Distribution. Marcel Dekker: New York, 1990.

7. Twede D. The process of logistical packaging innovation. Journal of Business Logistics 1992; 13(1): 69-94.

8. Azzi A, Battini D, Persona A, Sgarbossa, F. Packaging design: general framework and research agenda. Packaging Technology and Science 2012; 25(8): 435-456. DOI: $10.1002 /$ pts.993

9. Lee HL, Billington C. Managing supply chain inventory: pitfalls and opportunities. Sloan Management Review 1992; 33: 65-73.

10. Lee HL, Sasser MM. Product universality and design for supply chain management. Production Planning and Control 1995; 6(3): 270-77.

11. Sohrabpour V, Hellström D, Jahre M. Packaging in developing countries - Identifying supply chain needs. Journal of Humanitarian Logistics and Supply Chain Management 2012; 2(2): 183-205.

12. Jönson G. Packaging Technology for the Logistician, 2nd ed., Department of Design Sciences, Division of Packaging Logistics, Lund University: Lund, Sweden, 2000.

13. Kye D, Lee J, Lee KD. The perceived impact of packaging logistics on the efficiency of freight transportation (EOT). International Journal of Physical Distribution \& Logistics Management 2013; 43(8): 707-720.

14. Saghir M. Packaging Logistics Evaluation in the Swedish Retail Supply Chain, Licentiate thesis, Lund University: Lund, Sweden, 2002.

15. ECR Europe. Packaging in the sustainability agenda: a guide for corporate decision makers. 2009, Web site: [accessed 09 September 2014)].

16. Livingstone S, Sparks L. The new German packaging laws: effects on firms exporting to Germany. International Journal of Physical Distribution and Logistics Management 1994; 24 (7): 15-25. Doi.org/10.1108/09600039410070957

17. Robertson GL. Good and bad packaging: who decides? International Journal of Physical Distribution and Logistics Management 1990; 20(8): 37-41. DOI.org/10.1108/

18. Klevås J. Organization of packaging resources at a product-developing company. International Journal of Physical Distribution and Logistics Management 2005; 35(2): 116-31.

19. Prendergast G. The EC directive on packaging and packaging waste: current status and logistic implication. Logistics Information Management 1995; 8(3): 10-17. DOI.org/10.1108/09576059510091616 
20. Rundh B. Packaging design: creating competitive advantage with product packaging. British Food Journal 2009; 111(9): 988-1002.

21. Hellström, D, Saghir, M. Packaging and logistics interactions in retail supply chains. Packaging Technology and Science 2007; 20(3): 197-216. DOI: 10.1002/pts.754.

22. Olsson F. Systematisk Konstruktion. Doctoral thesis, Lund University: Lund, Sweden, 1976.

23. Garcia J, Prado JCP. Packaging design model from a supply chain approach. Supply Chain Management: An International Journal 2008; 13(5): 375-380.

24. Van Hoek R, Chapman P. How to move supply chain beyond cleaning up after new product development. Supply Chain Management: An International Journal 2007; 1(4): 239-44.

25. Sarkis J. A strategic decision framework for green supply chain management. Journal of Cleaner Production 2003; 11(4): 397-409

26. Chen KZ. Identifying the relationship among design methods: key to successful applications and developments of design methods. Journal of Engineering Design 1999; 10(2), 125-141.

27. Suh NP. Axiomatic design theory for systems. Research in Engineering Design 1998; 10(4): 189-209.

28. Suh NP. The Principles of Design, Oxford University Press, New York: 1990.

29. Fine C. Clockspeed-based strategies for supply chain design. Production and Operations Management 2000; 9(3): 213-21.

30. Ellram, LM, Stanley, LL. Integrating strategic cost management with a 3DCE environment: strategies, practices, and benefits. Journal of Purchasing and Supply Management 2008; 14(3): 180-191.

31. Ellram LM, Tate W, Carter C. Product-process-supply chain: an integrative approach to three-dimensional concurrent engineering. International Journal of Physical Distribution and Logistics Management 2007; 37(4): 305-330. Doi.org/10.1108/09600030710752523.

32. Fine C, Golany B, Naseraldin H. Modeling tradeoffs in 3-dimensional concurrent engineering: a goal programming approach. Journal of Operations Management 2005; 23(3-4): 389-403.

33. Dominic C. Packaging Logistics Performance, Doctoral thesis, Lund University: Lund, Sweden, 2011.

34. Olander-Roese M, Nilsson F. Competitive advantage through packaging design? Propositions for supply chain effectiveness and efficiency, Proceedings of ICED 09, 17th International Conference on Engineering Design, Palo Alto, CA, USA, 2009, 24-27.

35. Bramklev C, Bjärnemo R, Jönson G, Johnsson M. Towards an integrated design of product and packaging, Proceedings of ICED 04, $15^{\text {th }}$ International Conference on Engineering Design, Melbourne, Australia, Design Society, 15-18, 2005.

36. Yin KR. Case Study Research: Design and Methods, SAGE, Thousand Oaks (CA), USA, 2009.

37. Jones L, Somekh B. Observation in Somekh, B, Lewin C. (Eds.) Research Methods in the Social Sciences, SAGE: London, UK, 2005, 138-145. 
Page 13 of 22

Packaging Technology and Science

1
2
3
4
5
6
7
8
9
10
11
12
13
14
15
16
17
18
19
20
21
22
23
24
25
26
27
28
29
30
31
32
33
34
35
36
37
38
39
40
41
42
43
44
45
46
47
48
49
50
51
52
53
54
55
56
57
58
59
60

38. Bonner A, Littig B, Menz W. Interviewing Experts, Palgrave Macmillan: Chippenham, UK, 2009.

39. Corbin J, Strauss A. Basics of Qualitative Research, Sage, Thousand Oaks (CA), USA, 2008.

40. Marshall C, Rossman GB. Designing Qualitative Research. Sage: Thousand Oaks (CA), USA, 2006.

41. Svanes E, Vold M, Møller H, Pettersen MK, Larsen H, Hansen OJ. Sustainable packaging design: a holistic methodology for packaging design, Packaging Technology and Science, 2010; 23(3): 161-175.

42. Pail G, Beitz W, Feldhusen J, Grote K. Engineering Design a Systematic Approach, 3rd ed. Springer-Verlag, London, 2007.

43. Governs CPM. What and how about quality function deployment (QFD). International Journal Production Economics 1996; 46-47: 575-585, DOI: 10.1016/09255273(95)00113-1

http://mc.manuscriptcentral.com/pts 


\section{Table}

Table 1. Proposed supply chain focused Criteria Search Matrix (CSM) with expanded operational life cycle adapted from [22].

\begin{tabular}{|c|c|c|c|c|c|c|}
\hline & \multirow{2}{*}{\multicolumn{2}{|c|}{$\begin{array}{l}\text { Supply chain focused } \\
\text { CSM }\end{array}$}} & \multicolumn{4}{|c|}{ Evaluation criteria } \\
\hline & & & \multicolumn{3}{|c|}{ Requirements } & \multirow{2}{*}{$\begin{array}{l}\text { External constraints } \\
\text { Economic, legal, } \\
\text { environmental }\end{array}$} \\
\hline & & & Process & $\begin{array}{l}\text { Supply } \\
\text { chain }\end{array}$ & $\begin{array}{l}\text { Product and packaging } \\
\text { system }\end{array}$ & \\
\hline & & Weight & & & & \\
\hline \multirow{8}{*}{ 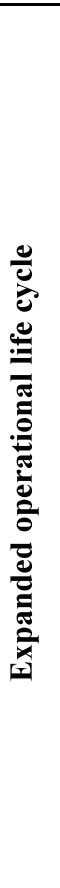 } & $\begin{array}{l}\text { Design \& } \\
\text { development }\end{array}$ & & & & & \\
\hline & $\begin{array}{l}\text { Sourcing \& } \\
\text { purchasing }\end{array}$ & & $v$ & & & \\
\hline & Production & & & & & \\
\hline & $\begin{array}{l}\text { Warehousing } \\
\& \text { handling }\end{array}$ & & & & & \\
\hline & Transport & & & & & \\
\hline & Marketing & & & & & \\
\hline & Use & & & & & \\
\hline & $\begin{array}{l}\text { Reduce/recycle } \\
\text { /reuse }\end{array}$ & & & & & \\
\hline
\end{tabular}




\section{Figures}

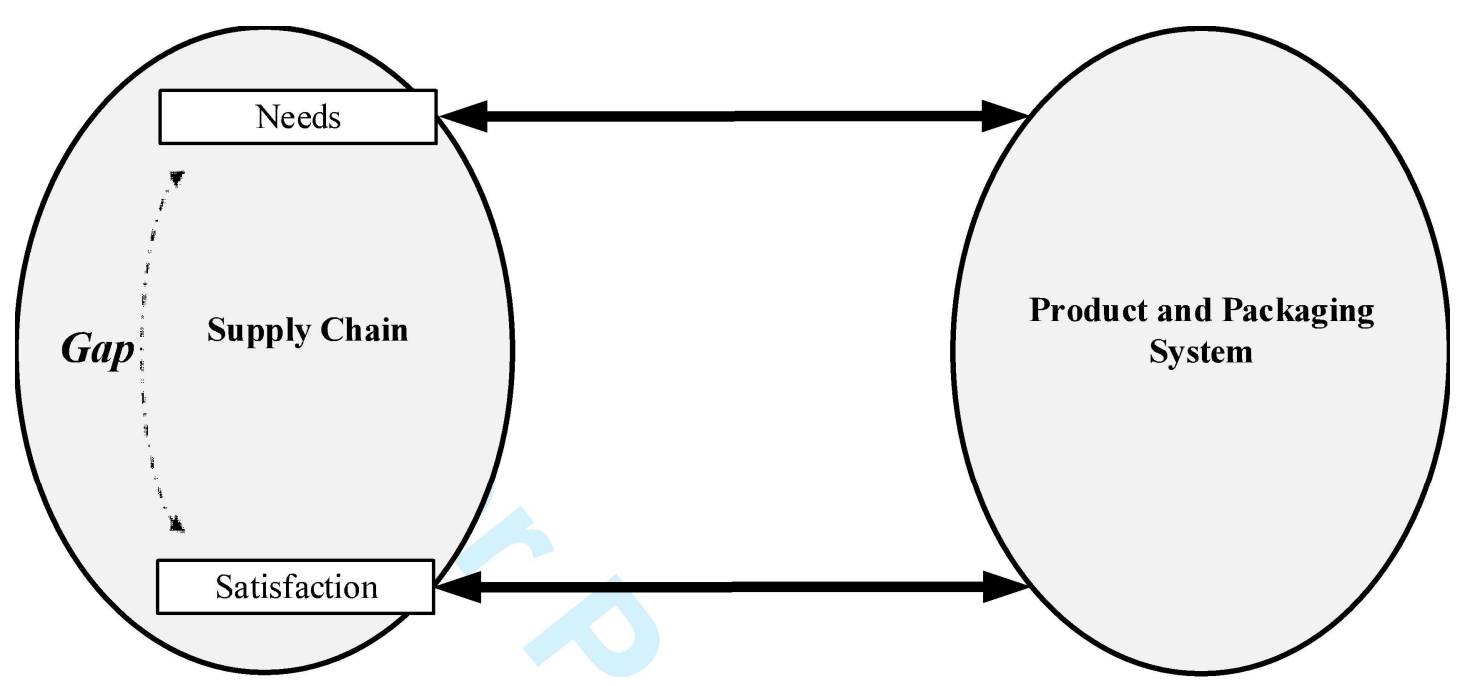

Figure 1. Gap between supply chain needs and satisfaction in interaction with the product and packaging system.

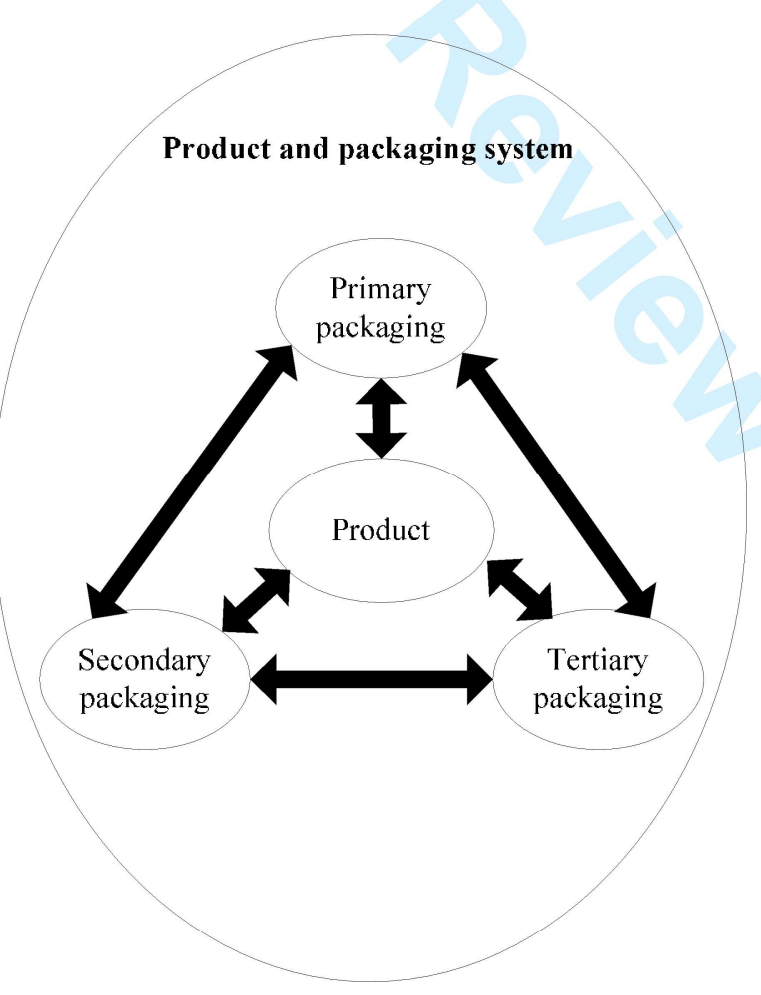


Figure 2. Product and packaging system model [11]. This figure illustrates components of the system: the product and the primary, secondary and tertiary packaging.

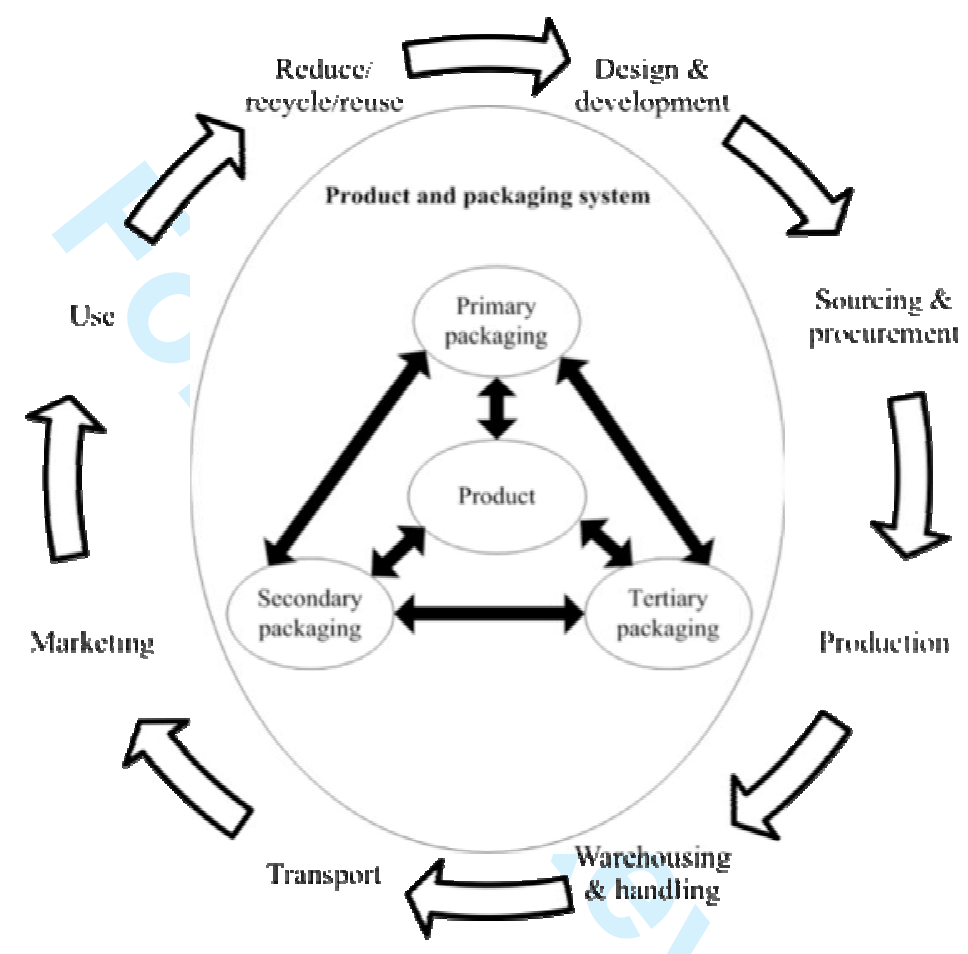

Figure 3. An expanded operational life cycle and a product and packaging system [11]. It starts with design and development and ends with reduce/recycle/reuse.

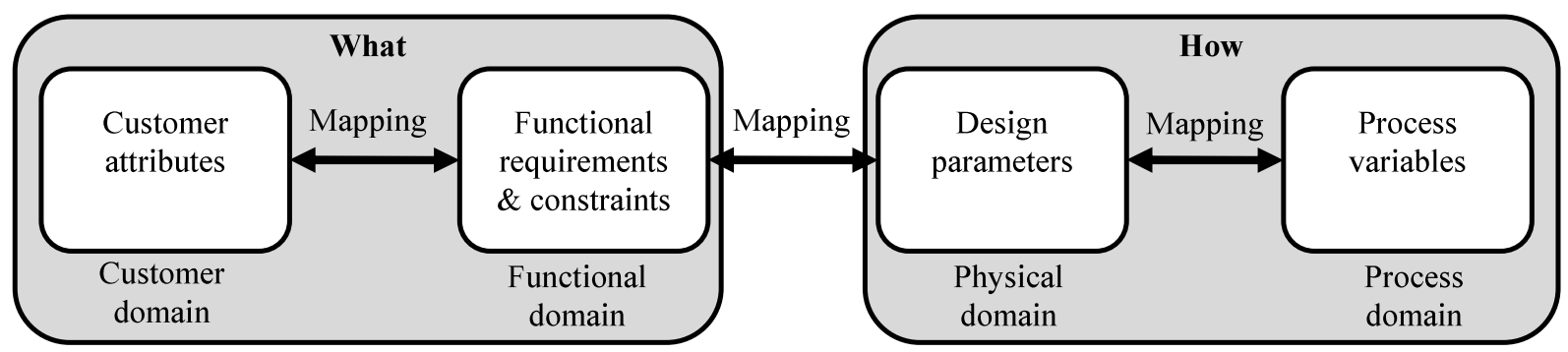

Figure 4. The four domains of design $[26,28]$ and the correlations between them. 


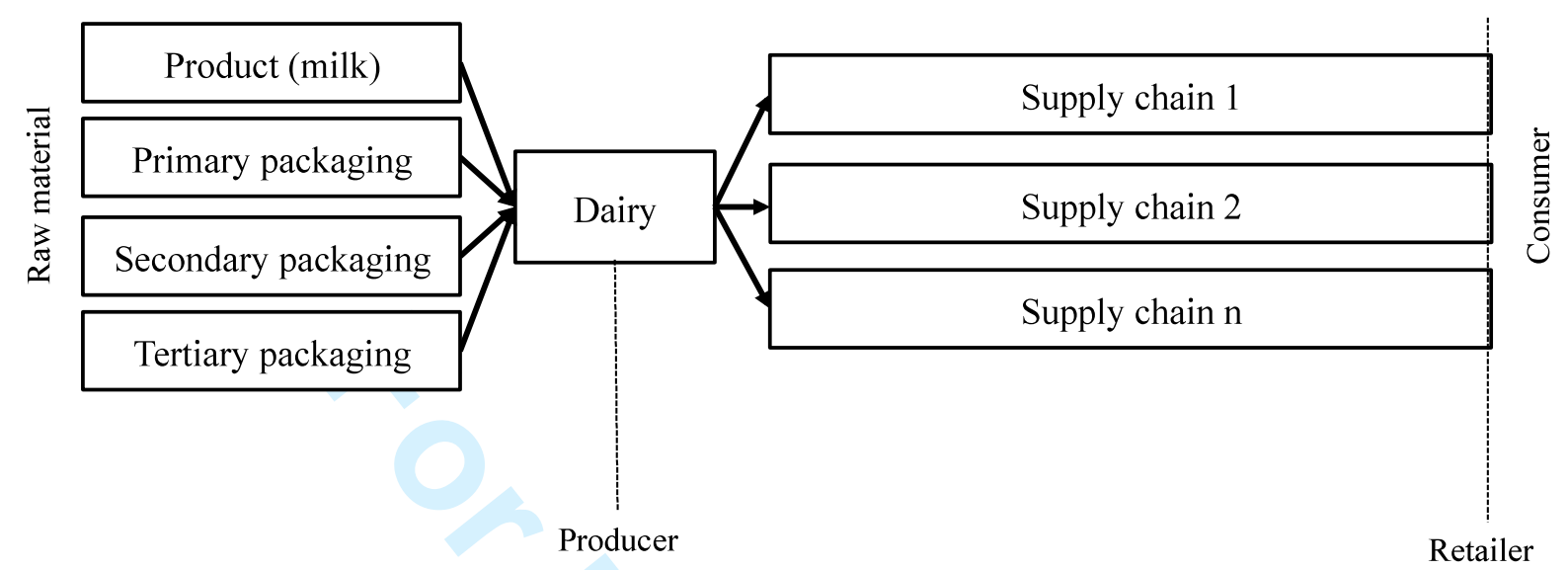

Figure 5. Supply chain in focus.

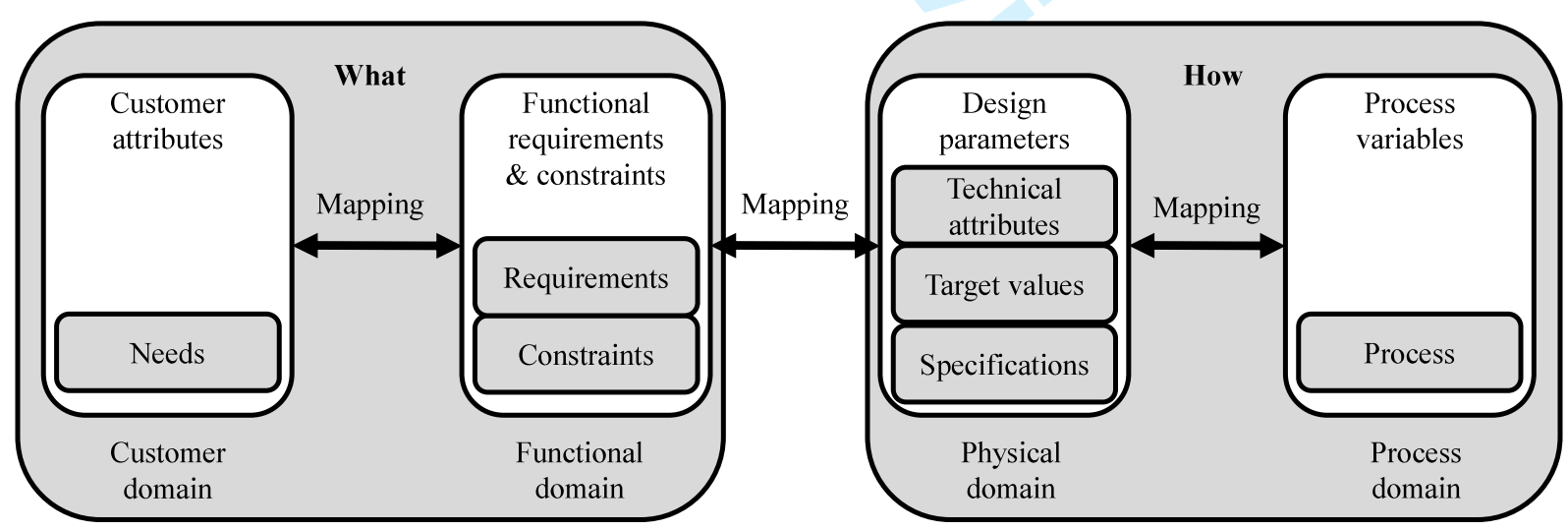

Figure 6. Packaging design and development in relation to the four domains of design $[26,28]$. 


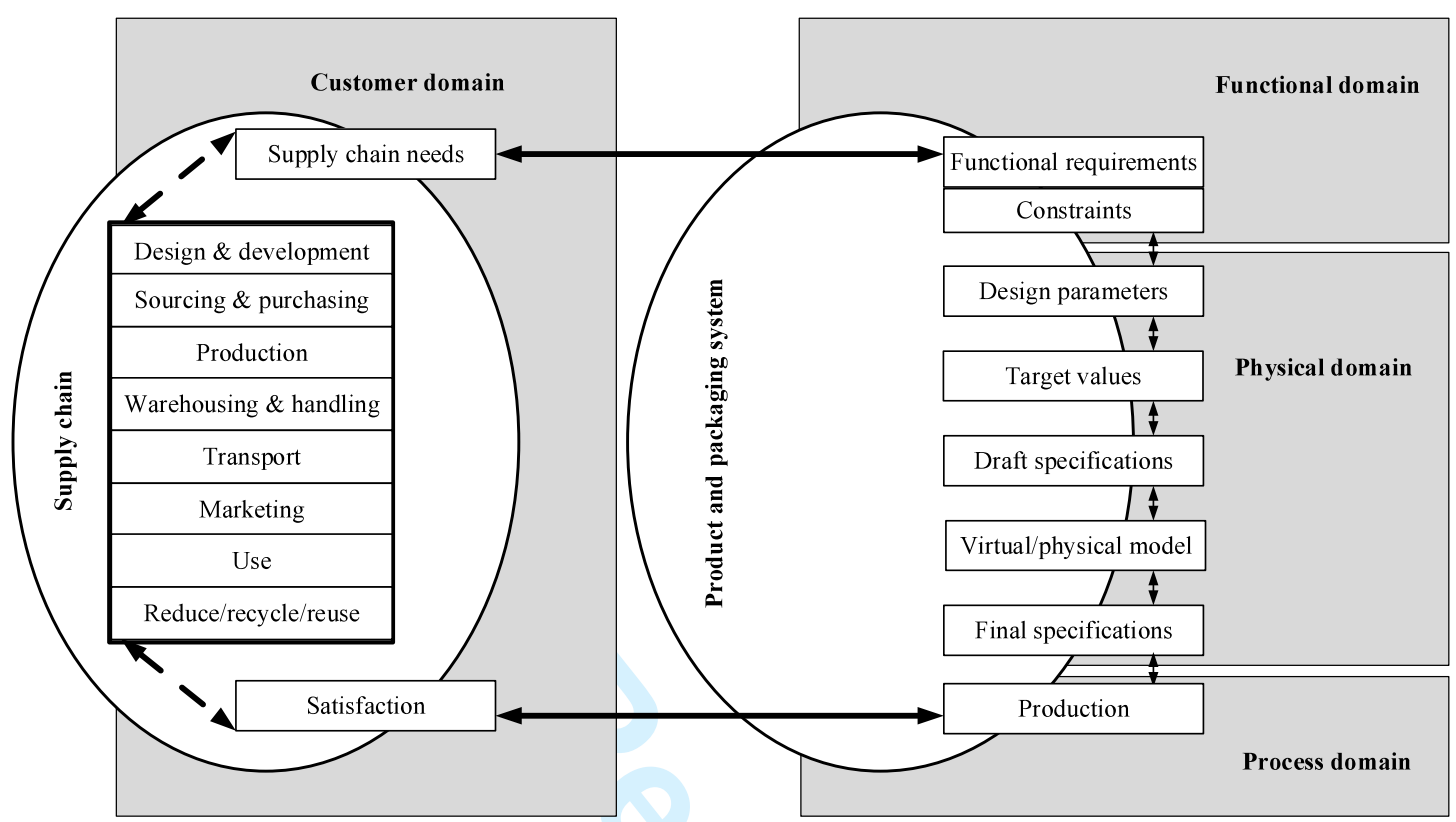

Figure 7. Supply chain focused packaging design and development method. Expanded operational life cycle, various steps from the PRC, and the four domains of design $[26,28]$ are used to illustrate the method. 


\section{Appendix}

This appendix provides an example of how the Package Requirement Cascading (PRC) method is used at Tetra Pak for secondary packaging development.

\section{Collection and structuring needs}

In the Criteria Search Matrix (CSM), the packaging life cycle and evaluation criteria are analysed in a matrix to collect and cover all needs (Table A1). Two dimensions of the matrix - packaging life cycle steps and evaluation criteria - are weighted in order of importance to indicate prioritised needs. These needs are then further analysed and broken down into more tangible and measurable requirements in the next step of the method.

$<$ Place Table A1 about here $>$

\section{Weighting the needs}

In the PRC and CSM, weighting is designed based on Pahl et al. 's [42] instructions: The first step in establishing the evaluation criteria is to assess the relative contribution of the requirements to the overall possible solutions. These assessments can be conducted by assigning weightings to each criterion that will be used in the following evaluation steps. These weightings are positive values and show the importance of the related criterion. Each assigned weighting shows the percentage of the contribution of each criterion to the overall possible solutions and the sum of them should be 1. For example, the different steps in the packaging life cycle (development, production, distribution, use, recycle/reuse) can have weightings of $0.3,0.15,0.3,0.2$ and 0.05 while using the CSM to design and develop secondary packaging (see Table A1). The evaluation criteria in the CSM have their own weightings (e.g. process 0.3 , environs 0.1 , human 0.2 and economy 0.4 ). The product of the multiplication of the weightings (life cycle weighting * evaluation criteria) is used as a final result in the PRC.

\section{Breaking down the needs into requirements}

All needs from the CSM are broken down into one or more requirements at this stage. Each requirement should be tangible and measureable and linked to a test method to determine whether the requirement is met. In the development process, each of these requirements is also assigned to a responsible organisation to add accountability to the method.

Continuing the weighting of the packaging life cycle and evaluation criteria in the CSM, requirements are also weighted according to how important each of them is to the needs. The CSM calculations are input to another matrix, called the Breakdown 
and Correlation Matrix (see Table A2, where an example is provided). Weighting is based on Pahl et al. 's [42] instructions with the same scale as Table A1.

$<$ Place Table A2 about here $>$

\section{Adding technical attributes}

Elements or characteristics are added to find the type of solution that fulfils relevant needs and requirements. In the PRC these are called "technical attributes" and for secondary packaging this means, for example, pallet size and box counts, as well as the technical characteristics of packaging material (see Table A3).

$<$ Place Table A3 about here $>$

\section{Correlating requirements with technical attributes}

The requirements and the technical attributes are correlated to each other to determine which attributes of all the available technical solutions most affect the final packaging solution. A correlation is carried out by assessing all requirements along with all the technical attributes. For each requirement criterion, all technical attributes are evaluated and correlated. Evaluation is similar to the importance rating in QFD (e.g. [43]). A scale of 0 to 4 is used to assign the correlation between requirements and technical requirements: $0=$ No correlations, $1=$ Weak correlation, $2=$ Medium correlation, $4=$ Strong correlation (see Table A3).

\section{Calculation of prioritised technical attributes}

Technical attributes are calculated after finishing the correlation, the weighting of needs, requirements and evaluation criteria. Each attribute that is correlated to any criteria will then be prioritised in a table in order of importance resulting in the draft specifications of the secondary packaging.

Table A1. Example of a completed CSM with weighted secondary packaging needs. 
Table A2. Example of breaking down a need into requirements in the Breakdown and Correlation Matrix. 
Table A3. Example of adding technical attributes in the Breakdown and Correlation Matrix.

\begin{tabular}{l|l|l|l|l|l|l}
\hline \hline \multirow{2}{*}{$\begin{array}{l}\text { Correlation between requirements and } \\
\text { technical attributes }\end{array}$} & \multicolumn{6}{l}{ Technical attributes } \\
\cline { 3 - 8 } & & $\begin{array}{l}\text { Box } \\
\text { strength }\end{array}$ & Thickness & $\begin{array}{l}\text { Box } \\
\text { length }\end{array}$ & $\begin{array}{l}\text { Box } \\
\text { width }\end{array}$ & $\begin{array}{l}\text { Box } \\
\text { height }\end{array}$ \\
\hline Requirements & & & & & & \\
\hline Pallet pattern & 0.02 & 0 & 1 & 4 & 4 & 2 \\
\hline Overhang/underhang & 0.02 & 0 & 2 & 2 & 2 & 2 \\
\hline Film wrapping & 0.01 & 0 & 0 & 0 & 0 & 0 \\
\hline Stacking stability & 0.01 & 0 & 0 & 1 & 1 & 1 \\
\hline Priority of technical attributes & & 0 & 0.06 & 0.13 & 0.13 & 0.13 \\
\hline \hline
\end{tabular}

